\title{
Plasma levels of soluble urokinase-type plasminogen activator receptor (suPAR) and early mortality risk among patients enrolling for antiretroviral treatment in South Africa

\author{
Stephen D Lawn*1,2, Landon Myer ${ }^{3,4}$, Nonzwakazi Bangani ${ }^{1}$, Monica Vogt ${ }^{1}$ \\ and Robin Wood ${ }^{1}$
}

Address: ${ }^{1}$ Desmond Tutu HIV Centre, Institute for Infectious Disease and Molecular Medicine, Faculty of Health Sciences, University of Cape Town, Cape Town, South Africa, ${ }^{2}$ Clinical Research Unit, Department of Infectious and Tropical Diseases, London School of Hygiene and Tropical Medicine, London, UK, ${ }^{3}$ Infectious Diseases Epidemiology Unit, School of Public Health and Family Medicine, Faculty of Health Sciences, University of Cape Town, South Africa and ${ }^{4}$ Department of Epidemiology, Mailman School of Public Health, Columbia University, New York, USA

Email: Stephen D Lawn* - stevelawn@yahoo.co.uk; Landon Myer - Imyer@cormack.uct.ac.za; Nonzwakazi Bangani - nbangani@curie.uct.ac.za; Monica Vogt - monica.vogt@hiv-research.org.za; Robin Wood - robin.wood@hiv-research.org.za

* Corresponding author

Published: 17 May 2007

BMC Infectious Diseases 2007, 7:4I doi:10.1 I86/I47I-2334-7-4I

This article is available from: http://www.biomedcentral.com/|47|-2334/7/4I

(C) 2007 Lawn et al; licensee BioMed Central Ltd.

This is an Open Access article distributed under the terms of the Creative Commons Attribution License (http://creativecommons.org/licenses/by/2.0), which permits unrestricted use, distribution, and reproduction in any medium, provided the original work is properly cited.

\begin{abstract}
Background: Serum concentrations of soluble urokinase-type plasminogen activator receptor (suPAR) have a strong independent association with HIV-I-related mortality. The practical utility of plasma suPAR in assessing short-term all-cause mortality risk was evaluated in patients with advanced immunodeficiency enrolling in an antiretroviral treatment (ART) programme in South Africa.
\end{abstract}

Methods: An enzyme-linked immunosorbent assay (ELISA) was used to measure plasma concentrations of suPAR in patients at the time of enrolment to the ART programme. The association between plasma suPAR concentrations, baseline patient characteristics and cohort outcomes after 4 months of ART were determined.

Results: Patients ( $n=293,70 \%$ female) had a median age of 33 years and were followed up for a median of 5 months from enrolment. The median CD4 cell count was 47 cells/ $\mu \mathrm{l}(\mathrm{IQR}=22-72)$ and $38 \%$ of patients had WHO stage 4 disease. 218 (74\%) patients remained alive after 4 months of ART; 39 (I3\%) died and $36(12 \%)$ were lost to the programme for other reasons. Patients who died had significantly higher plasma suPAR concentrations compared to those who either survived $(P<0.0 \mathrm{I})$ or left the programme for other reasons $(P<0.043)$. In multivariate analysis, higher $\log _{10}$ suPAR concentrations were significantly associated with lower CD4 cell counts, WHO clinical stage 4 disease and male sex. In multivariate analysis to identify factors associated with death, $\log _{10}$ suPAR concentration was the most strongly associated variable $(P<0.00 I)$. However, examination of sensitivity and specificity characteristics using receiver operating characteristic (ROC) analysis revealed that results from this assay did not have a discriminatory cut-point to provide clinically useful information.

Conclusion: Plasma suPAR concentration was the strongest independent predictor of short-term mortality risk among patients with advanced immunodeficiency enrolling in this ART programme. However, lack of a discriminatory threshold did not permit this marker to be used to triage patients according to short-term mortality risk. 


\section{Background}

In 2005 an estimated 25.8 million adults and children in sub-Saharan Africa were living with HIV/AIDS; 4.7 million were in immediate need of antiretroviral treatment (ART) and 2.4 million died [1,2]. Access to ART in the region is expanding and is estimated to have averted 250,000-350,000 deaths in low- and middle-income countries in 2005 alone [3]. Early pessimism that ART could not be effectively delivered on a large scale using a simplified public health approach has largely proven unfounded, at least in the short term. ART access has been rapidly expanded on a massive scale in Lusaka, Zambia, for example, and on a country-wide scale in Malawi with generally good early clinical outcomes [4,5]. However, an important issue to emerge in ART programmes in resource-limited settings is that, following initiation of ART, early mortality is very high [6].

In cohorts in sub-Saharan Africa, on-treatment mortality during the first 12 months of ART ranges between $7 \%$ and $26 \%$ and predominantly occurs within the initial months of ART [4,7-11]. A report from a South African cohort also found that mortality occurring in the one month period while patients were preparing for ART accounted for $67 \%$ of early in-programme deaths [7]. This suggests that even short delays in starting ART may be associated with considerable mortality risk. Mortality is also likely to accrue as a result of delays within the health system upstream of ART programmes [12]. Additional delays may arise due to the practical constraints imposed by the sheer numbers of patients seeking to start treatment in some settings and this may require some form of patient prioritisation.

Delays in starting ART must be minimised for those at high risk of death. Identification of a simple laboratory assay that provides prognostic information beyond that provided by blood CD4 cell count might provide a means of identifying those at highest mortality risk. Such a triage tool might facilitate prioritisation of patients, permitting more rapid initiation of ART and higher intensity medical follow-up in those at greatest risk of death. Low blood haemoglobin and increased serum concentration of $\mathrm{B}_{2}$ microglobulin, for example, are each independently associated with mortality $[4,10,13]$. However, the additional prognostic value of these parameters is somewhat limited.

The plasma concentration of soluble urokinase-type plasminogen activator receptor (suPAR, CD87) is a strong independent predictor of mortality in untreated patients with HIV-1 infection $[14,15]$ and levels decrease in parallel with the response to ART [16]. Plasma concentrations of this immune marker can be quickly and inexpensively measured using a simple enzyme-linked immunosorbent assay (ELISA), which requires much less sophisticated laboratory infrastructure than that needed for CD4 cell count or plasma viral load measurement. Such an assay might therefore be potentially useful in resource-limited settings, especially as the assay could potentially be further simplified to a clinic-based point of care test and could use urine rather than serum [17]. The practical utility of measurements of this immune marker, however, has not been adequately evaluated within clinical HIV services.

We have previously described a community-based ART programme in Cape Town, South Africa, in which mortality rates, risk factors and causes have been reported in detail $[7,11,18,19]$. In this study we examined the prognostic utility of plasma suPAR concentrations among HIV-infected patients with advanced immunodeficiency and high risk of mortality.

\section{Methods \\ Antiretroviral treatment programme}

The ART service based at the Gugulethu Community Health Centre, in Cape Town, South Africa has previously been described [20-22]. The district it serves has a predominantly African population of over 300,000, the vast majority of whom live in conditions of low socioeconomic status. In 2003 the antenatal HIV seroprevalence was $28 \%$. Patients are referred from primary care HIV clinics in the community to the ART programme. Treatment criteria are based on the WHO 2002 recommendations [23], which include those with a prior AIDS diagnosis (WHO stage 4 disease) or a blood CD4 cell count $<200$ cells $/ \mu \mathrm{l}$.

The mean time between enrolment of a patient in the service and initiation of ART is approximately one month, permitting thorough evaluation of patients (including screening for tuberculosis) and preparation for treatment as described previously $[7,11,20,21]$. Blood samples are routinely drawn on all patients at a standard clinic visit during this period to measure CD4 cell counts by flow cytometry (FACSCount ${ }^{\mathrm{TM}}$, Becton Dickinson, Franklin Lakes, NJ, USA) and plasma viral load using Versant ${ }^{\mathrm{TM}}$ HIV-1 RNA 3.0 branched chain DNA assay (Bayer HealthCare, Leverkusen, Germany). Excess EDTA plasma is stored at $\leq-80^{\circ} \mathrm{C}$.

First-line ART, comprised of stavudine, lamivudine plus a non-nucleoside reverse transcriptase inhibitor (efavirenz or nevirapine), was supplied free of charge. Treatment adherence and viral load suppression $<400$ copies $/ \mathrm{ml}$ in this cohort both exceed $90 \%$ at all 16 weekly follow-up time-points [20]. All patients with CD4 counts $<200$ cells/ $\mu \mathrm{l}$ received prophylaxis with daily cotrimoxazole or dapsone as an alternative but isoniazid prophylaxis was not used. In addition to scheduled clinic appointments at 4, 8, and 16 weeks and 16-weekly thereafter, patients had open access to the clinic for medical problems. 
Assignment of each patient to a community-based therapeutic counsellor promotes high levels of treatment compliance and also high levels of data-completeness so that final outcomes are known for the vast majority of patients. A proportion of patients did not initiate treatment for a variety of reasons other than death and such individuals were deferred from the programme and follow-up was censored at the time they exited the programme. Principal causes of death in this cohort have been previously been described in detail and include wasting syndrome, acute sepsis, tuberculosis, malignancy and immune reconstitution disease (mainly associated with cryptococcal meningitis) $[7,19,24]$.

Structured clinical records were maintained on all patients screened on entry to the ART programme and this information was transferred on a weekly basis to a computer database. All patients enrolling in studies at this ART clinic provide written informed consent and this study was approved by the Research Ethics Committee of the University of Cape Town.

\section{Plasma suPAR concentrations}

Total plasma suPAR concentrations were measured at a single time-point in plasma samples that had been stored at the time of programme enrolment. In order to assess this prognostic marker a patient population with high mortality risk, we selected all patients who enrolled into the programme between September 2002 and February 2005 and who had a CD 4 cell count $\leq 100$ cells $/ \mu l$.

Plasma suPAR concentrations were measured using a commercially available enzyme-linked immunosorbent assay (ELISA) (suPARnostic, ${ }^{\text {тм }}$ ViroGates, Lyngby, Denmark) following the manufacturer's instructions. This is a simple double monoclonal antibody sandwich assay that measures total suPAR, including both full-length and cleaved forms of the receptor. In brief, a standard control curve (range $0.6-19.3 \mathrm{ng} / \mathrm{ml}$ ), positive control, and test samples were incubated in duplicates in a 96-well plate pre-coated with anti-suPAR antibody. Following further incubation with a secondary peroxidase-conjugated antibody, the assay was developed by addition of a tetramethylbenzidine (TMB) chromogenic substrate. The reaction was terminated by addition of sulphuric acid and absorbance at $450 \mathrm{~nm}$ was determined using a microtitre plate reader. The linear standard curve was used to determine concentrations in positive control and test samples. Samples with concentrations exceeding the highest standard (19.3 ng/ml) were reanalysed using a further 5-fold sample dilution.

\section{Data analysis}

Outcomes for all patients were determined from the time of entry to the programme until completion of 4 months
ART or exit from the programme due to death or other causes. Data were analysed using STATA Version 9.0 (College Station, Texas, USA) and GraphPad Prism 4.0 (GraphPad Software Inc. San Diego, CA, USA). As the frequency distribution of values was highly right-skewed, the suPaR values were $\log _{10}$-transformed for bivariate analyses (based on the Mann Whitney U or Kruskall Wallis tests to compare medians) and multivariate modelling. We constructed multiple linear regression models to predict suPAR values at programme enrolment, and used Cox's proportional hazards to examine the associations between suPAR concentrations and the relative hazard of mortality. For the latter set of models, time at risk was calculated from entry into the programme to the first of death, transfer out of the programme, loss to-follow-up, or the 4 month follow-up visit on ART. Receiver operating characteristic (ROC) curves were constructed to examine the effect of different cut-points of $\log _{10}$ suPAR values on the sensitivity and specificity of predicting mortality during the study period. Confidence intervals for the area under the ROC curves were calculated using the method described by Bamber [25].

\section{Results}

Patient baseline characteristics and follow-up

Of patients who enrolled into the ART programme between September 2002 and February 2005, 354 had a blood CD4 cell count $\leq 100$ cells $/ \mu$ l. Of these, a stored plasma sample was available for measurement of suPAR concentration in $293(83 \%)$ patients and these were included in the study. These patients had a median age of 33 years and approximately two-thirds were female (Table 1). $89 \%$ had either WHO stage 3 or 4 disease. A total of $43 \%$ of patients had either an active diagnosis of TB prior

Table I: Patient characteristics $(n=293)$

\begin{tabular}{lc}
\hline Age median (IQR), years & $33(29-38)$ \\
Female sex & $205(70)$ \\
Median (IQR) CD4 cell count & $47(22-72)$ \\
WHO Stage & \\
I/2 & $32(I I)$ \\
$\quad 3$ & $150(5 I)$ \\
$\quad 4$ & $111(38)$ \\
Viral load > I05 copies/ml & $149(5 I)$ \\
Tuberculosis, & \\
Present at enrolment & $80(27)$ \\
Developed during ART & $47(16)$ \\
Median (IQR) duration & \\
follow up (days) & $145(139-173)$ \\
Outcome & \\
Alive on ART & $218(74)$ \\
Deaths pre or during ART & $39(13)$ \\
Non-death losses & $36(12)$
\end{tabular}

Baseline characteristics and outcome of patients enrolling in the antiretroviral treatment (ART) programme who were included in the analysis. Unless otherwise stated, values are numbers (\%) of patients. 
to initiation of ART or developed symptoms during the first 4 months of ART that were due to confirmed incident TB.

Twenty-four ( $8 \%)$ patients did not start ART due to death before starting treatment $(n=13)$ or other reasons $(n=$ 11 ), including treatment refusal, loss to follow-up or access to treatment at another clinic. A total of $269(92 \%)$ patients did start ART. Of these, 218 (82\%) were retained within the programme and were alive after 16 weeks of treatment. Twenty six $(9.7 \%)$ patients died within the first 16 weeks of treatment. Other programme losses during ART included 15 (5.6\%) patients who moved out of area and $10(3.7 \%)$ who were lost to follow-up. The median (IQR) total period of follow-up was 145 days (139-173) and was comprised of a median pre-ART period of 34 days (28-56) and a median of 112 days (112-119) on ART.

\section{Plasma suPAR concentrations}

Detectable levels of suPAR were measured in plasma samples from all 293 patients. The standard curves for each run were linear (mean $\mathrm{r}^{2}=0.995 ; \mathrm{SD}=0.004$ ) and all positive control readings were consistent with the expected value. The median suPAR concentration in the patient plasma samples was $4.05 \mathrm{ng} / \mathrm{ml}$ (IQR, 3.03-5.77; range $1.14-52.4 \mathrm{ng} / \mathrm{ml})$ or $0.607 \log _{10} \mathrm{ng} / \mathrm{ml}(\mathrm{IQR}=0.481-$ $0.761)$.

Associations between baseline patient characteristics and $\log _{10}$ suPAR concentrations were examined (Table 2). In unadjusted analyses, low baseline CD4 cell counts and WHO stage 4 disease were strongly associated with higher $\log _{10}$ plasma concentrations of suPAR. There was also a trend towards patients with active $\mathrm{TB}$ diagnoses having higher suPAR concentrations. When the cases of tubercu- losis were subdivided into those with active $\mathrm{TB}$ at the time of the blood sample and those who developed later tuberculosis during ART, neither group was significantly associated with suPAR concentration. Other baseline characteristics, however, were not significantly associated with suPAR concentrations. In adjusted analyses, the association with CD4 cell count and WHO stage remained, but female sex was also found to be significantly associated with lower suPAR concentrations (Table 2).

\section{Patient outcomes and suPAR concentrations}

To examine the association between $\log _{10}$ serum suPAR concentrations and clinical outcome, patients were divided into three groups according to final outcome: (i) received ART and alive after 4 months treatment $(\mathrm{n}=218$, $74 \%)$; (ii) died during the analysis period $(\mathrm{n}=39,13 \%)$; or (iii) other programme losses $(n=36,12 \%)$. Among those who died, 13 died before starting ART and 26 died during the first 4 months of ART.

The median log suPAR concentration among patients who died $(0.761 \mathrm{ng} / \mathrm{ml}, \mathrm{IQR}=0.548-0.949 \mathrm{ng} / \mathrm{ml})$ was significantly greater than that of patients who remained alive on ART $($ median $=0.583 \mathrm{ng} / \mathrm{ml}, \mathrm{IQR}=0.479-0.715 \mathrm{ng} / \mathrm{ml}$ ) or who were lost to the programme for reasons other than death $($ median $=0.609 \mathrm{ng} / \mathrm{ml} \mathrm{ng} / \mathrm{ml} ; \mathrm{IQR}=0.429-0.833$ $\mathrm{ng} / \mathrm{ml}$ ) (Figure 1). However, concentrations did not differ significantly comparing those who remained alive with non-death losses. Thus, higher suPAR concentrations were strongly associated with mortality. However, median suPAR concentrations were almost identical comparing those who died pre-ART with those who died during the first 4 months of ART (5.92 and $5.93 \mathrm{ng} / \mathrm{ml}$, respectively) and suPAR concentrations were not associated with causes of death (data not shown).

Table 2:

\begin{tabular}{|c|c|c|c|c|c|c|}
\hline \multirow[t]{2}{*}{ Patient characteristic } & \multicolumn{3}{|c|}{ Unadjusted association } & \multicolumn{3}{|c|}{ Adjusted association } \\
\hline & $\begin{array}{c}\text { Mean change log suPAR per unit } \\
\text { increase in variable }\end{array}$ & $95 \% \mathrm{Cl}$ & $P$ value & $\begin{array}{l}\text { Mean change log suPAR per unit } \\
\text { increase in variable }\end{array}$ & $95 \% \mathrm{Cl}$ & $P$ value \\
\hline Age (years) & $-0,0001$ & $\begin{array}{c}-0.0038 \\
0.0035\end{array}$ & 0.944 & 0.0018 & $\begin{array}{c}-0.0020 \\
0.0056\end{array}$ & 0.353 \\
\hline Female & -0.0362 & $\begin{array}{c}-0.0950 \\
0.0226\end{array}$ & 0.227 & -0.0615 & $\begin{array}{l}-0.1228 \\
-0.0002\end{array}$ & 0.049 \\
\hline CD4 cell count (cells/ $\mu$ l) & -0.0014 & $\begin{array}{l}-0.0026 \\
-0.0005\end{array}$ & 0.003 & -0.0012 & $\begin{array}{l}-0.0022 \\
-0.0029\end{array}$ & 0.011 \\
\hline $\log _{10}$ viral load (copies/ml) & 0.0328 & $\begin{array}{c}-0.0149 \\
0.0806\end{array}$ & 0.177 & 0.0219 & $\begin{array}{c}-0.0253 \\
0.0691\end{array}$ & 0.361 \\
\hline WHO stage $I, 2,3$ versus 4 & 0.0691 & $\begin{array}{l}0.0140 \\
0.1243\end{array}$ & 0.014 & 0.0566 & $\begin{array}{l}-0.0003 \\
0.1136\end{array}$ & 0.051 \\
\hline Tuberculosis (all cases) & 0.0482 & $\begin{array}{l}-0.0087 \\
0.1051\end{array}$ & 0.097 & 0.0380 & $\begin{array}{c}-0.0187 \\
0.0947\end{array}$ & 0.189 \\
\hline
\end{tabular}

Crude associations between baseline patient characteristics and $\log 10$ plasma suPAR concentrations (ng/ml) measured at baseline. 


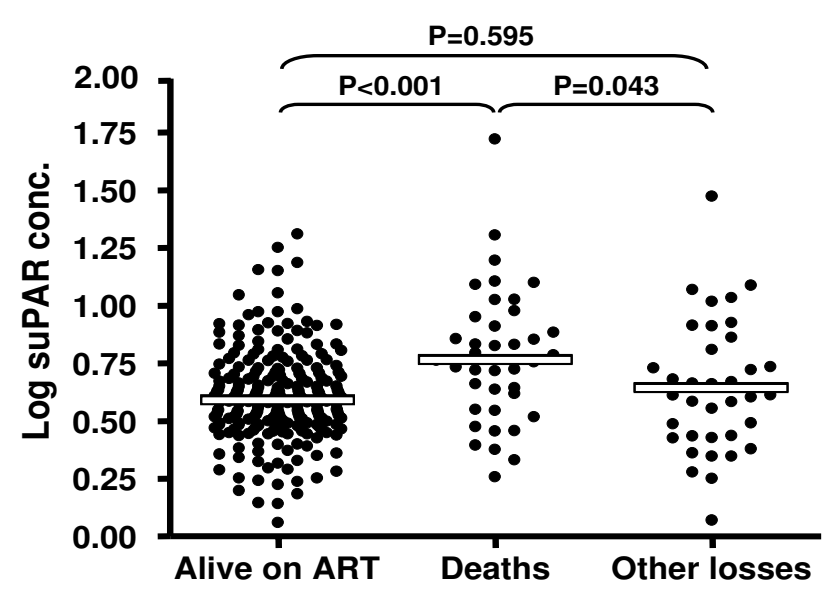

Figure I

$\log _{10}$ suPAR concentrations among patients $(n=293)$ enrolling in an antiretroviral treatment (ART) programme. Individual data points represent individual patients who were either receiving ART and alive after completing 4 months of treatment $(n=218)$, had died before starting ART or during the first 16 weeks of treatment $(n=39)$, or were lost to the programme $(n=36)$. Group median values are shown by a bar.

\section{Predictors of mortality}

We next examined predictors of mortality using multivariate analysis. In an initial model that included baseline patient characteristics but excluded suPAR concentration, only baseline CD4 cell count was significantly associated with mortality. There was also a strong trend towards an association with WHO clinical stage (Table 3a). However, when the log concentration of plasma suPAR was included in the model, the strength of the associations with CD4 cell count and WHO stage were diminished and log suPAR concentration was found to be the strongest independent predictor of mortality (Table 3).

Having demonstrated that plasma suPAR concentration was strongly associated with mortality at a group level, we next examined the utility of this as a prognostic test to be applied to individual patients. To do this, receiver operating characteristic (ROC) curve analysis was done (Figure $2)$. The area under the ROC curve was moderate $(0.681$; 95\% CI 0.582-0.781) and yet a clear cut-point that maximised the ability of suPAR concentration to distinguish between patients who died or survived was lacking. Using cut-points of $\geq 5.0 \mathrm{ng} / \mathrm{ml}, \geq 10.0 \mathrm{ng} / \mathrm{ml}$ or $\geq 15 \mathrm{ng} / \mathrm{ml}$, the corresponding sensitivity and specificity values showed that none of these cut-offs provided sufficient sensitivity and specificity that would be clinically useful in this patient population (Figure 2).

\section{Discussion}

In this study we examined the utility of plasma suPAR concentrations for predicting all-cause mortality among HIV-infected patients with advanced immunodeficiency early in an ART programme in South Africa. Our observations add to previous findings from Europe that plasma suPAR is an independent predictor of mortality in untreated cohorts of HIV-infected persons [14,15]. We also found that mortality was more strongly associated with suPAR concentration than with any other risk factor including CD4 cell count and WHO clinical stage. However, despite these strong associations, there was no useful cut-point in the distribution of suPAR concentrations that could discriminate adequately between groups with higher and lower mortality risk. Thus, the marker was unable to serve as a useful adjunctive tool to assess shortterm mortality risk in this patient population.

SuPAR is a component of the plasminogen activation system, which comprises urokinase-type plasminogen activator ( $\mathrm{uPA}$ ) and its receptor (UPAR) [26]. uPAR is expressed on a variety of different immune cells and vascular endothelial cells. It is involved in the recruitment of leukocytes from the circulation to extravascular sites of inflammation through regulatory effects on pericellular proteolysis, cell adhesion, chemotaxis, and signal transduction [26,27]. suPAR is generated by either proteolytic cleavage or shedding from cells. Serum concentrations are increased and prognostic in a variety of inflammatory and

Table 3:

\begin{tabular}{|c|c|c|c|c|c|c|}
\hline Characteristic & (a) Hazard ratio & $95 \% \mathrm{Cl}$ & P value & (b) Hazard ratio & $95 \% \mathrm{Cl}$ & $P$ value \\
\hline Age & 1.00 & $0.96-1.05$ & 0.844 & 1.00 & $0.96-1.04$ & 0.985 \\
\hline Male & 1.30 & $0.65-2.60$ & 0.464 & 1.68 & $0.84-3.39$ & 0.142 \\
\hline Baseline CD4 cell count & 0.99 & $0.97-1.00$ & 0.028 & 0.99 & $0.98-1.00$ & 0.059 \\
\hline $\log _{10}$ Viral load (copies/ml) & 0.94 & $0.50-1.78$ & 0.848 & 0.85 & $0.45-1.61$ & 0.612 \\
\hline WHO stage 4 & 1.91 & $0.98-3.73$ & 0.059 & 1.62 & $0.83-3.16$ & 0.162 \\
\hline Tuberculosis (all cases) & 1.13 & $0.59-2.17$ & 0.710 & 0.95 & $0.49-1.86$ & 0.883 \\
\hline Log suPAR concentration $\mathrm{ng} / \mathrm{ml}$ & - & - & - & 9.96 & $2.78-35.7$ & $<0.001$ \\
\hline
\end{tabular}

Cox proportional hazards model showing the association between baseline characteristics of patients $(n=293)$ and subsequent death before starting antiretroviral treatment (ART) or during the first 16 weeks ART. The first model (a) shows associations with baseline patient characteristics whereas the second model (b) also includes plasma log suPAR concentration. 


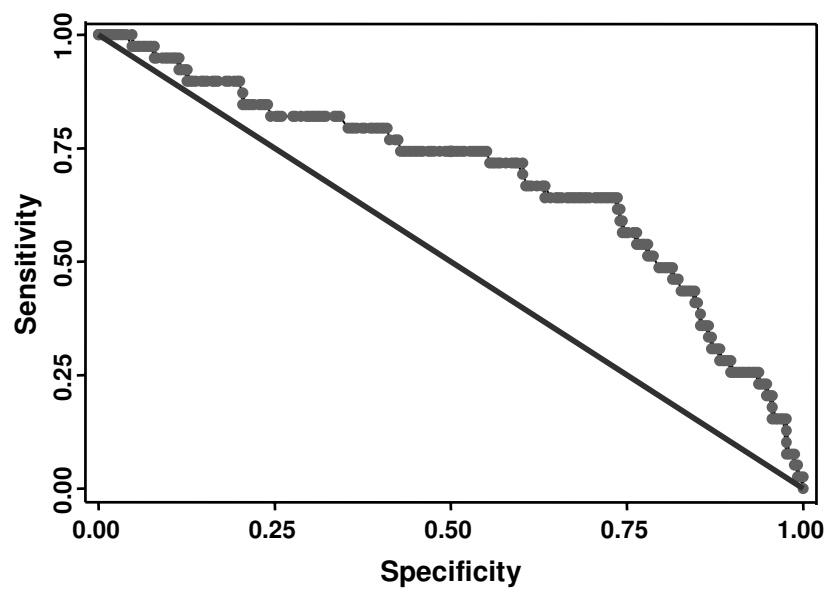

\begin{tabular}{|c|c|c|}
\hline Cut-point $\mathbf{n g} / \mathrm{ml}$ & Sensitivity & Specificity \\
\hline$\geq 5.0$ & 50.0 & 72.7 \\
\hline$\geq 10.0$ & 14.3 & 96.2 \\
\hline$\geq 15.0$ & 6.0 & 99.0 \\
\hline
\end{tabular}

\section{Figure 2}

Receiver operating characteristic (ROC) curve analysis showing the utility of plasma suPAR concentration as a prognostic test predicting death up to the first 4 months of ART. The area under the curve is $0.68 \mathrm{I}$.

neoplastic disease states, including HIV infection, tuberculosis, sepsis, rheumatoid arthritis and certain malignancies and suPAR concentrations reflect prognosis in these disease states $[14,15,17,28-30]$.

In European cohorts of HIV-infected patients plasma suPAR concentrations were higher among those with more advanced clinical stages of disease $[14,15]$. This is likely to reflect the fact that systemic immune activation increases with HIV disease progression and is central to the pathogenesis of the infection [31]. In this study we also found that higher suPAR concentrations were significantly associated with advanced WHO stage of disease and lower blood CD4 cell counts. Absolute levels reported in this patient population are consistent with those found in previous studies $[14,15]$. High suPAR concentrations were also found to be weakly associated with male sex. This has not previously been reported although it is interesting that male sex was an independent risk factor for early mortality in several African ART cohorts $[4,11,32]$. Although tuberculosis has been found to be associated with increased supAR levels [28] there was no such association in this study. This may reflect the fact that those who were free of tuberculosis may have had a high frequency of other opportunistic infections, which also increase
suPAR concentrations, thereby masking any association with TB.

The association between high suPAR concentrations and mortality was highly statistically significant both at a group level (Figure 1) and in multivariate analysis (Table $3)$. However, the distributions of suPAR concentrations in those who survived and those who died were very broadly overlapping (Figure 1). This is likely to reflect the fact that suPAR is a non-specific inflammatory marker with a continuous distribution. As a result, using ROC analysis it was not possible to identify a useful cut-point that provided adequate sensitivity and specificity to enable the assay to be used to discriminate those at highest risk of death. This assay could therefore not be used to triage patients according to mortality risk as they enrolled into this ART programme.

A strength of this study is that we studied patients in a community-based service that is likely to be representative of other public sector ART clinics elsewhere in sub-Saharan Africa. Moreover, a cohort rather than case control design reduced potential for patient selection bias. Completeness of outcome data in this cohort was high due to active community-based follow-up of patients using peer counsellors. Some patients who were lost to the programme for reasons other than death may have subsequently died. However, these patients were categorised separately in the group analysis and their median suPAR concentration did not differ from that of the group who remained alive. Previous studies have only examined associations between plasma suPAR concentrations and prognosis in HIV-infected patients at a group level. This is the first study to evaluate the practical clinical utility of this marker in a clinical setting.

The study assessed short-term mortality risk over a median of 5 months from enrolment. An important reason for this is that we have previously reported that deaths in this period are strongly associated with baseline patients characteristics [11] whereas deaths occurring beyond this period are only associated with response to ART. Previous studies of the prognostic value of suPAR concentration have reported on much longer durations of follow-up of 3 years [15] and 5 years [14] in natural history cohorts. Plasma suPAR concentrations may have greater prognostic value in assessing long-term mortality risk when assessed in patients with less advanced immunodeficiency. However, short-term mortality risk is of greatest relevance to clinicians making clinical decisions and for developing treatment guidelines $[33,34]$.

Only patients with advanced immunodeficiency were included and the restricted cohort composition may have diminished the association between mortality and risk 
factors such as $\mathrm{CD} 4$ cell count. This would also explain the lack of association with plasma viral load [35]. Despite the cohort composition, the association between mortality and plasma suPAR concentrations was nevertheless very strong at a group level. The data from this study are relevant to patients with advanced disease who are already eligible for ART and cannot be generalised to those with earlier disease. Whether this assay can provide useful prognostic information relevant to when ART should be started needs to be assessed in future studies. This will depend on whether the distribution of suPAR concentrations in patients with earlier stages of disease has a discriminatory threshold.

In conclusion, at a group level plasma suPAR concentrations are strongly predictive of mortality among HIVinfected patients in sub-Saharan Africa, confirming the findings of previous studies in Europe. However, the lack of a cut-point that provides adequate sensitivity and specificity to predict mortality in this patient population prevented this assay from providing clinically useful prognostic information for individual patient management.

\section{Competing interests}

The author(s) declare that they have no competing interests.

\section{Authors' contributions}

SDL, RW and LM designed the study and analysis. NB and MV did the laboratory work. SDL wrote the manuscript with critical input from RW and LM. All authors read and approved the final manuscript

\section{Acknowledgements}

SDL is funded by the Wellcome Trust, London, UK with grant 07464 I/ZI $04 / Z$. LM and RW are all funded in part by the National Institutes of Health, USA, through CIPRA grant IUI9AI53217-0I. The authors are grateful to staff at the Hannan Crusaid antiretroviral clinic in Gugulethu and to the staff of the Desmond Tutu HIV Centre. The suPARnostic ELISA assays were kindly provided by ViroGates, Lyngby, Denmark.

\section{References}

I. UNAIDS/WHO: AIDS epidemic update: December 2005.

2. UNAIDS WHO: Progress on global access to HIV antiretroviral therapy. A report by " 3 by 5" and beyond. March 2006.

3. WHO/UNAIDS: Press release: HIV infection rates decreasing in several countries but global number of people living with HIV continues to rise. November, 2005. [http://www.who.int/ hiv/epiupdate2005/en/print.html].

4. Stringer JS, Zulu I, Levy J, Stringer EM, Mwango A, Chi BH, Mtonga V, Reid S, Cantrell RA, Bulterys M, Saag MS, Marlink RG, Mwinga A, Ellerbrock TV, Sinkala M: Rapid scale-up of antiretroviral therapy at primary care sites in Zambia: feasibility and early outcomes. JAMA 2006, 296:782-793.

5. Harries AD, Schouten EJ, Libamba E: Scaling up antiretroviral treatment in resource-poor settings. Lancet 2006, 367:1870-1872.

6. Braitstein P, Brinkhof MW, Dabis F, Schechter M, Boulle A, Miotti P, Wood R, Laurent C, Sprinz E, Seyler C, Bangsberg DR, Balestre E, Sterne JA, May M, Egger M: Mortality of HIV-I-infected patients in the first year of antiretroviral therapy: comparison between low-income and high-income countries. Lancet 2006, 367:817-824.

7. Lawn SD, Myer L, Orrell C, Bekker LG, Wood R: Early mortality among adults accessing a community-based antiretroviral service in South Africa: implications for programme design. AIDS 2005, I9:2I4I-2| 48 .

8. Weidle PJ, Malamba S, Mwebaze R, Sozi C, Rukundo G, Downing R, Hanson D, Ochola D, Mugyenyi P, Mermin J, Samb B, Lackritz E: Assessment of a pilot antiretroviral drug therapy programme in Uganda: patients' response, survival, and drug resistance. Lancet 2002, 360:34-40.

9. Zachariah R, Fitzgerald M, Massaquoi M, Pasulani O, Arnould L, Makombe S, Harries AD: Risk factors for high early mortality in patients on antiretroviral treatment in a rural district of Malawi. AIDS 2006, 20:2355-2360.

10. Etard JF, Ndiaye I, Thierry-Mieg M, Gueye NF, Gueye PM, Laniece I, Dieng AB, Diouf A, Laurent C, Mboup S, Sow PS, Delaporte E: Mortality and causes of death in adults receiving highly active antiretroviral therapy in Senegal: a 7-year cohort study. AIDS 2006, 20:1181-1189.

II. Lawn SD, Myer L, Harling G, Orrell C, Bekker LG, Wood R: Determinants of mortality and nondeath losses from an antiretroviral treatment service in South Africa: implications for program evaluation. Clin Infect Dis 2006, 43:770-776.

12. Lawn SD, Wood R: How can earlier entry of patients into antiretroviral programs in low-income countries be promoted? Clin Infect Dis 2006, 42:43 I-432.

13. Ullum H, Lepri AC, Katzenstein TL, Phillips AN, Skinhoj P, Gerstoft J, Pedersen BK: Prognostic value of single measurements of beta-2-microglobulin, immunoglobulin $A$ in HIV disease after controlling for CD4 lymphocyte counts and plasma HIV RNA levels. Scand J Infect Dis 2000, 32:37I-376.

14. Sidenius N, Sier CF, Ullum H, Pedersen BK, Lepri AC, Blasi F, EugenOlsen J: Serum level of soluble urokinase-type plasminogen activator receptor is a strong and independent predictor of survival in human immunodeficiency virus infection. Blood 2000, 96:409|-4095.

15. Ostrowski SR, Piironen T, Hoyer-Hansen G, Gerstoft J, Pedersen BK, Ullum $\mathrm{H}$ : High plasma levels of intact and cleaved soluble urokinase receptor reflect immune activation and are independent predictors of mortality in HIV-I-infected patients. Acquir Immune Defic Syndr 2005, 39:23-31.

16. Ostrowski SR, Katzenstein TL, Piironen T, Gerstoft J, Pedersen BK, Ullum H: Soluble urokinase receptor levels in plasma during 5 years of highly active antiretroviral therapy in HIV-Iinfected patients. J Acquir Immune Defic Syndr 2004, 35:337-342.

17. Sier CF, Sidenius N, Mariani A, Aletti G, Agape V, Ferrari A, Casetta G, Stephens RW, Brunner N, Blasi F: Presence of urokinase-type plasminogen activator receptor in urine of cancer patients and its possible clinical relevance. Lab Invest 1999, 79:717-722.

18. Lawn SD, Myer L, Bekker LG, Wood R: Early mortality in patients with HIV-associated tuberculosis in Africa: implications for time to initiation of treatment.Programme and absracts of the 13th Conference on Retroviruses and Opportunistic Infections (CROI).Los Angeles, USA.February 2007.Abstract \#0-I 26.

19. Lawn SD, Bekker LG, Myer L, Orrell C, Wood R: Cryptococcocal immune reconstitution disease: a major cause of early mortality in a South African antiretroviral programme. AIDS 2005, 19:2050-2052.

20. Bekker LG, Myer L, Orrell C, Lawn S, Wood R: Rapid scale-up of a community-based HIV treatment service: programme performance over 3 consecutive years in Guguletu, South Africa. S Afr Med J 2006, 96:3 I5-320.

21. Lawn SD, Myer L, Bekker LG, Wood R: Burden of tuberculosis in an antiretroviral treatment programme in sub-Saharan Africa: impact on treatment outcomes and implications for tuberculosis control. AIDS 2006, 20:1605-1612.

22. Lawn SD, Myer L, Bekker LG, Wood R: CD4 cell count recovery among HIV-infected patients with very advanced immunodeficiency commencing antiretroviral treatment in subSaharan Africa. BMC Infect Dis 2006, 6:59.

23. Organisation. WH: Scaling up Antiretroviral Therapy in Resource-limited Settings: Guidelines for a Public Health Approach; Executive Summary. Geneva: World Health 
Organisation 2002. Accessed 15.04.05: http//www.who.int/ hiv/pub/prev-care/en/WHO_ARV_Guidelines.pdf. .

24. Lawn SD, Myer L, Bekker LG, Wood R: Tuberculosis-associated immune reconstitution disease: incidence, risk factors and impact in an antiretroviral treatment service in South Africa. AIDS 2007, 21:335-34l.

25. Bamber $D$ : The area above the above the ordinal dominance graph and the area below the receiver operating characteristic curve graph. Journal of Mathematical Psychology 1975:387-4I5.

26. Ossowski L, guirre-Ghiso JA: Urokinase receptor and integrin partnership: coordination of signaling for cell adhesion, migration and growth. Curr Opin Cell Biol 2000, 12:613-620.

27. Preissner KT, Kanse SM, May AE: Urokinase receptor: a molecular organizer in cellular communication. Curr Opin Cell Biol 2000, I 2:621-628.

28. Eugen-Olsen J, Gustafson P, Sidenius N, Fischer TK, Parner J, Aaby P, Gomes VF, Lisse I: The serum level of soluble urokinase receptor is elevated in tuberculosis patients and predicts mortality during treatment: a community study from GuineaBissau. Int J Tuberc Lung Dis 2002, 6:686-692.

29. Slot O, Brunner N, Locht H, Oxholm P, Stephens RW: Soluble urokinase plasminogen activator receptor in plasma of patients with inflammatory rheumatic disorders: increased concentrations in rheumatoid arthritis. Ann Rheum Dis 1999, 58:488-492.

30. Florquin S, van den Berg JG, Olszyna DP, Claessen N, Opal SM, Weening JJ, van Der PT: Release of urokinase plasminogen activator receptor during urosepsis and endotoxemia. Kidney Int 200I, 59:2054-206I.

31. Lawn SD, Butera ST, Folks TM: Contribution of immune activation to the pathogenesis and transmission of human immunodeficiency virus type I infection. Clin Microbiol Rev 200I, 14:753-77, table.

32. Ferradini $L$, Jeannin $A$, Pinoges $L$, lzopet J, Odhiambo D, Mankhambo L, Karungi G, Szumilin E, Balandine S, Fedida G, Carrieri MP, Spire B, Ford N, Tassie JM, Guerin PJ, Brasher C: Scaling up of highly active antiretroviral therapy in a rural district of Malawi: an effectiveness assessment. Lancet 2006, 367:1335-1342.

33. Phillips A: Short-term risk of AIDS according to current CD4 cell count and viral load in antiretroviral drug-naive individuals and those treated in the monotherapy era. AIDS 2004 I 8:5I-58.

34. Badri M, Lawn SD, Wood R: Short-term risk of AIDS or death in people infected with HIV-I before antiretroviral therapy in South Africa: a longitudinal study. Lancet 2006, 368: $1254-1259$

35. Cozzi Lepri A, Katzenstein TL, Ullum H, Phillips AN, Skinhoj P, Gerstoft J, Pedersen BK: The relative prognostic value of plasma HIV RNA levels and CD4 lymphocyte counts in advanced HIV infection. AIDS 1998, 12:1639-1643.

\section{Pre-publication history}

The pre-publication history for this paper can be accessed here:

http://www.biomedcentral.com/1471-2334/7/41/prepub
Publish with Biomed Central and every scientist can read your work free of charge

"BioMed Central will be the most significant development for disseminating the results of biomedical research in our lifetime. "

Sir Paul Nurse, Cancer Research UK

Your research papers will be:

- available free of charge to the entire biomedical community

- peer reviewed and published immediately upon acceptance

- cited in PubMed and archived on PubMed Central

- yours - you keep the copyright
BioMedcentral 